\title{
Readiness of Nurses to Provide Nursing Care for COVID-19 Patients at COVID Dedicated Hospitals in Dhaka, Bangladesh
}

\author{
Gazi MHUR ${ }^{1}$, Akhi MR ${ }^{2}$ \\ ${ }^{l}$ Department of Graduate Nursing, Bangabandhu Sheikh Mujib Medical University, Dhaka, \\ Bangladesh ${ }^{2}$ Uppazilla Health Complex, Morelganj, Bagerhat, Bangladesh
}

\begin{abstract}
Background: Coronavirus pandemic has become the leading cause of disability and death throughout the world. Nurses have a pivotal role in managing the COVID-19 patients across the globe including Bangladesh.

Objective: The study was aimed to assess the level of nurses' knowledge, attitude and practice with regard to readiness for providing nursing care for COVID-19 patients at COVID-19 dedicated hospitals in Dhaka.

Method: This is a cross-sectional descriptive study. Data were collected from July, to September, 2020 using a self-administered questionnaire. A total of 384 nurses were selected from four corona dedicated hospitals in Dhaka. Nurses' readiness was measured by using paper and pencil questionnaire. Personal and professional characteristics knowledge, attitudes and practice related to COVID-19 questionnaires were used. Data were analysed using descriptive statistics, independent t-test, one way ANOVA and Pearson's Product-Moment Correlation-Coefficient.
\end{abstract}

Results: Findings showed that nurses had moderate level of knowledge $(\mathrm{M}=34.34 .15, \mathrm{SD}=2.98)$, attitude $(\mathrm{M}=27.58, \mathrm{SD}=3.45)$ and practice $(\mathrm{M}=13.12, \mathrm{SD}=1.78)$ respectively. A significant negative correlation found between knowledge and attitude $(\mathrm{r}=-.178, p=.000)$. However, no significant relationship was to be found between attitude and practice and knowledge and practice regarding nurses' readiness to provide nursing care to COVID-19 patients. Statistical analysis showed that nurses working at Kurmitola General Hospital $(\mathrm{F}=9.47, p=.000)$ had better practice than those of other hospitals. Senior staff nurses did better practice $(\mathrm{F}=21.765, p=.000)$ than those of other nurses.

Conclusion: Nurses achieved moderate level of knowledge, attitude and practice. There was negative correlation between knowledge and attitude of nurses. In-service education programme can be developed and conducted to increase knowledge, attitude and practice regarding nurses readiness for caring of COVID-19 patients.

Keywords: COVID-19 patient, Nursing care, Nurses readiness, Frontline health care workers

\section{Introduction}

Coronavirus is a severe acute respiratory syndrome known as COVID-19 which is caused by a novel human coronavirus. ${ }^{1}$ It was first noticed in December 2019, among the patients with pneumonia in Wuhan city, China and considered to be as the significant health problem throughout the world. $^{2}$ COVID-19 was declared as a global pandemic on 11 March 2020 by World Health Organization. ${ }^{3}$ Globally, around 5,430115 confirmed cases and 1,316,994 deaths have been reported whereas around 434472 confirmed cases and 6,215- deaths reported in Bangladesh. ${ }^{4,5}$

According to the Institute of Epidemiology, Disease Control and Research (IEDCR), about 8000

*Correspondence: Md. Harun Ur Rashid Gazi, Department of Graduate Nursing, Bangabandhu Sheikh Mujib Medical University, Dhaka, Bangladesh; e-mail:harunurrashidl@gmail.com;ORCID:https//orcid.org/0000-0003-1489-8723 healthcare workers including 2723 doctors, 1943 nurses and some 3201 other health staff were infected with this virus. International Council of Nurses estimated that at least 90,000 healthcare workers had been infected by COVID-19 and mortality could be more than 20,000. Among them about 1500 nurses had died in the novel coronavirus pandemic globally and among them 15 nurses died in Bangladesh. ${ }^{7}$ Nurses are at the frontline of COVID- 19 pandemic fighter and are exposed to, not only infection with COVID-19 due to their frequent exposure to infected individuals, but also psychological distress, long working hours, fatigue, occupational stigma and physical violence. ${ }^{8}$

COVID-19 is transmitted from person-to-person by close contact via the respiratory secretions in coughs or sneezes or by touching virus-contaminated surfaces or objects. Older people with chronic 
illnesses have been identified as possible risk for morbidity and mortality. ${ }^{9}$ Approximately, $20 \%$ of COVID-19 cases had experienced respiratory distress syndrome, sepsis, septic shock, and organ failure. ${ }^{10}$ Regular hand washing, social distancing, and respiratory hygiene (covering mouth and nose while coughing or sneezing) can prevent the transmission of COVID-19. ${ }^{11}$ Common symptoms include fever, cough, fatigue, shortness of breath, and loss of sense of smell. Complications may include pneumonia and acute respiratory distress syndrome. The time from exposure to onset of symptoms is typically around five days but may range from two to fourteen days. ${ }^{12-14}$

Nurses' readiness is an important aspect to prevent the spread of COVID-19 among the people and manage the corona affected patients effectively. Nurses' readiness is defined as nurses' knowledge, attitudes and practice regarding COVID-19 disease. Previous study in Bangladesh reported that nurses had poor of knowledge about transmission and symptoms onset of corona virus, and incubation period of COVID-19. ${ }^{15}$ Prior study also reported that nurses inadequate knowledge, incorrect attitude can directly influence toward their practices and lead to delayed diagnosis, poor infection control practice and spread of disease. ${ }^{16,17}$

A small number of nurses were given training through video conferencing which was not enough. Therefore, most of the nurses are providing care to the COVID-19 patient without receiving any training on COVID-19 infection. ${ }^{18,19}$ Absence of isolation facilities, contaminated environment and nurses' inadequate knowledge and attitudes of infection control practices increase the incidence and prevalence of COVID-19. ${ }^{20}$ Nurses are now being infected due to lack of training on donning and doffing of PPE, proper disposal of PPE, and lack of negative air pressure knowledge in intensive care units. As a result, a huge number of nurses are getting infected repeatedly with this deadly virus. ${ }^{21}$

Nurses play a key role and act as frontline fighters for the prevention and control of COVID 19 outbreak and safe patient care. ${ }^{22}$

Indeed, nurses' inadequate knowledge, attitude and practice can delay recognition and handling of potential COVID-19 patients during the pandemic period. However, the nurses' readiness such as knowledge, attitude and practice toward COVID-19 remains unclear as very limited studies are conducted on this arena. In this regard, the COVID-19 pandemic offers a unique opportunity to explore the level of knowledge, attitude and practice of nurses during this global health disaster. The purpose of the study was to investigate the level of knowledge, attitude, and practice of the risk of infection with COVID-19 among the nurses working at COVID dedicated hospitals in Bangladesh. The findings of this study will help as baseline data for policy makers and programmer to develop COVID-19 training programmes for nurses to provide better care towards corona affected patients during the outbreak.

\section{Methods and Materials}

A cross-sectional descriptive study design was performed to examine the level of nurses' knowledge, attitude, and practice regarding COVID-19 infection at COVID dedicated hospitals in Dhaka. The nurses who were working at COVID-19 dedicated hospitals were the participants in the study. Four COVID dedicated hospitals from Dhaka were randomly selected as study settings. The selected hospitals were Bangabandhu Sheikh Mujib Medical University Hospital (BSMMUH), Dhaka Medical College Hospital (DMCH), Mugda Medical College Hospital $(\mathrm{MMCH})$ and Kurmitola General Hospital (KGH). Data were collected from the $1^{\text {st }}$ July 2020 to $30^{\text {th }}$ July2020. The nurses, who were providing care of corona patients, had ability to speak, read, write and understand Bengali language and who were conscious were included into the study. The subjects who were not interested to participate were excluded from the study. A convenience sampling technique was used to select participants. The sample size was calculated using EpiCalc-2000 based on the following assumption: the proportion of good knowledge $50 \%$, level of confidence $95 \%$ and precision $5 \%$, and design effect 1 to be 384 . Then the sample size was increased by $5 \%$ to overcome nonresponse. Confidentiality precautions were ensured during the data collection process.

The survey comprised 65 items (closed-ended questions) which take about $30-40 \mathrm{~min}$ to complete. The survey was divided into six parts, including 1) participants demographic questionnaire (7 items), 2) knowledge questionnaire (24 items) with yes/no/don't know options, 3) attitude questionnaire (7 items) with 5 -point Likert scale ranging from $1=$ strongly disagree to $5=$ strongly agree, 4) practice questionnaire (10 items) with 3-point Likert scale ranging from $3=$ always to $1=$ never, 5) source of COVID-19information (6 items) with yes/no option and 6) hospital facilities related questionnaire (11 items) sheet, informed consent 
form and questionnaire. In knowledge section, participants were asked to answer the question with yes/no/don't know responses. Each correct answer received 1 (one) point while incorrect answer received 0 (zero) point. The total score was ranged from 0 to 24 and the score was then converted into percentages. The knowledge was categorized into three levels: low $(<33 \%)$, moderate $(33.01 \%$ to $66 \%)$ and high $(>66 \%)$. High score indicates high level of knowledge towards COVID-19 infection. In attitudes section, participants were asked to rate their opinion against 5-point Likert scale which was ranged from 1 = strongly disagree, $2=$ disagree, $3=$ undecided, $4=$ agree, $5=$ strongly agree. The total score was ranged from 7 to 35 and converted into percentages. Attitude was categorized into three levels: negative $(<33 \%)$, neutral $(33.01 \%$ to $66 \%$ ), and positive (>66\%). High score indicate positive attitudes towards COVID-19 infection. A 10 -item practice questionnaire was used to measure the nurses practice level of COVID-19 infection. The participants were asked to rate their opinion against each of the statement which was ranged from $3=$ always, $2=$ occasional or 3 $=$ never. The total score was ranged from 10 to 30 and converted into percentages. The practice was categorized into three levels: low $(<33 \%)$, moderate $(33.01 \%$ to $66 \%)$, high (>66\%). High score indicates high level of practice of nurses. In reference to source of information, participants were asked to answer the questions with yes/no options. High score indicates better knowledge on COVID-19 infection. With respect to hospital facilities, 11 items were asked to answer with yes/no options. Higher score indicates better hospital facilities for nurses regarding COVID-19 patient management. All data were entered into computer software. Statistical analysis was performed using IBM SPSS software for Windows version 21 (NY, USA). Descriptive statistics was applied to calculate proportions and frequencies. The independent t-test, one way of ANOVA, and Pearson correlation test was used to investigate the level of association among study variables. A $p$-value of less than 0.05 was considered statistically significant.

Prior to collecting the data, the proposal was approved by the Institutional Review Board of BSMMU, Shahbagh, Dhaka. Permission was taken from the competent authority of the selected hospitals. Researcher communicated with the hospital authority and nursing superintendent and informed them about the study objectives. The researcher then met with the study participants in the selected hospitals and explained them about the purpose, procedure and benefit of the study in details. Confidentiality and privacy of the nurses was strictly maintained. Anonymity was guaranteed. Nurses were ensured that their participation in the study was completely voluntary and they could withdraw their participation from the study at any time without any reasons or penalty. A 96 set of questionnaire in each of the settings was kept on a desk near to the nursing superintendent office. Nurses who were interested to participate in the study picked up the questionnaire from the desk voluntarily on a first-come-first-serve basis and dropped the questionnaire into the box after they completed them. Researcher then collected all completed questionnaire from the box. The informed consent was taken in the written forms from all the participants.

\section{Results}

Considering source of information of COVID-19 (table I), majority of nurses $(92.0 \%)$ collected their COVID-19 related information from international health organization sites followed by news media $(87.0 \%)$, government official sites and media $(84.0 \%)$, social media (81.0\%) and journal (45.0\%).

Table I: Distribution of sources of COVID information among the nurses $(\mathrm{n}=384)$

\begin{tabular}{lcc}
\hline COVID information & $\begin{array}{c}\text { Yes } \\
\mathbf{n}(\%)\end{array}$ & $\begin{array}{c}\text { No } \\
\mathbf{n}(\%)\end{array}$ \\
\hline $\begin{array}{l}\text { International health organization } \\
\text { sites }\end{array}$ & $354(92.0)$ & $30(8.0)$ \\
$\begin{array}{l}\text { Government official sites and } \\
\text { media }\end{array}$ & $321(84.0)$ & $36(16.0)$ \\
News media & $335(87.0)$ & $49(13.0)$ \\
Social Media & $311(81.0)$ & $74(19.0)$ \\
Journal & $172(45.0)$ & $212(55.0)$ \\
Information sources of others & $60(16.0)$ & $324(84.0)$ \\
\hline
\end{tabular}

Withregard to hospital facilities (table II), only $37.0 \%$ nurses had received basic training on COVID-19 and same percent of nurses received hand hygiene training. However nearly half of the respondents $(47.0 \%)$ received training on use of PPE and $38.0 \%$ nurses had received training on environmental prevention. Above half of the nurses $(51.0 \%)$ stated that hospital provided dedicated area for risk assessment of COVID-19 patients. Around 58.0\% nurses reported that liquid soaps were available at the communal area in the hospitals. Most of the nurses $(63.0 \%)$ said that rules and facilities for maintaining physical distance was existed in the hospitals. Most of the nurses (77.0\%) also mentioned that quarantine facilities were provided for nurses with suspected symptoms. Large portion of nurses $(75.0 \%)$ 
reported that hospital authority encouraged nurses to stay home with COVID-19 symptoms.

Table II: Distribution of hospital facilities among the nurses $(\mathrm{N}=384)$

\begin{tabular}{|c|c|c|}
\hline \multirow{2}{*}{ Hospital facilities } & \multirow{2}{*}{$\begin{array}{c}\text { Yes } \\
\text { n (\%) }\end{array}$} & \multirow{2}{*}{$\begin{array}{c}\text { No } \\
\text { n (\%) }\end{array}$} \\
\hline & & \\
\hline Basic training on COVID -19 & $142(37.0)$ & $242(63.0)$ \\
\hline Training on hand hygiene & $142(37.0)$ & $242(63.0)$ \\
\hline Training on use of PPE & 181(47.0) & 203(53.0) \\
\hline $\begin{array}{l}\text { Training on environmental } \\
\text { prevention }\end{array}$ & $148(38.0)$ & $236(62.0)$ \\
\hline $\begin{array}{l}\text { Maintain registry for moving } \\
\text { people in hospital }\end{array}$ & $120(31.0)$ & $264(69.0)$ \\
\hline $\begin{array}{l}\text { Risk assessment for all entering } \\
\text { people }\end{array}$ & $177(46.0)$ & $207(54.0)$ \\
\hline Dedicated area for risk assessment & $196(51.0)$ & $188(49.0)$ \\
\hline $\begin{array}{l}\text { Liquid soap available in communal } \\
\text { area }\end{array}$ & $222(58.0)$ & $162(42.0)$ \\
\hline $\begin{array}{l}\text { Rules and facilities in place for } \\
\text { physical distancing }\end{array}$ & $235(61.0)$ & $149(39.0)$ \\
\hline $\begin{array}{l}\text { Quarantine for nurses with } \\
\text { suspected symptoms }\end{array}$ & 297(77.0) & $87(23.0)$ \\
\hline $\begin{array}{l}\text { Encourage staffs to stay at home } \\
\text { with COVID-19 symptoms }\end{array}$ & $290(75.0)$ & $94(25.0)$ \\
\hline
\end{tabular}

The result found that the total mean score of nurses knowledge on COVID-19 was 34.15 (SD=2.98) ranging from 28-47, which indicated moderate level of knowledge. The mean attitude score was calculated as $27.58(\mathrm{SD}=3.45)$ ranging from 7-35 which indicated neutral attitude. However total mean score of practice was $13.12 \quad(\mathrm{SD}=1.78)$ ranging from 10-20 which indicated moderate level (table III).

Table III: Descriptive statistics of nurses level of knowledge, attitude and practice $(\mathrm{n}=384)$

\begin{tabular}{lcccc}
\hline Variables & Mean & SD & Range & Level \\
\hline Knowledge & 34.20 & 2.90 & $28-47$ & Moderate \\
Attitudes & 27.60 & 3.50 & $15-35$ & Moderate \\
Practice & 13.10 & 1.80 & $10-20$ & Moderate \\
\hline
\end{tabular}

Table IV illustrates the association between study places and practice score of nurses regarding COVID-19. Result shows that there was a statistically significant relationship between study places and nurses practice score $(\mathrm{F}=9.47, p=.000)$. It means that nurses' practice at BSMMU was better than those of nurses' practice at $\mathrm{MMCH}, \mathrm{DMCH}$ and Kurmitola General Hospital.

Table IV: Association between working place and practice of Nurses $(n=384)$

\begin{tabular}{llcccc}
\hline Variable & Category & $\mathbf{n}(\boldsymbol{\%})$ & $\mathbf{M} \pm \mathbf{S D}$ & $\mathbf{t} / \mathbf{r} / \mathbf{F}$ & $\boldsymbol{p}$ \\
\hline Place & BSMMU & $96(25.0)$ & $13.48 \pm 1.19$ & 9.47 & .000 \\
& & & & & \\
& DMCH & $96(25.0)$ & $13.30 \pm 1.55$ & & \\
& MMCH & $96(25.0)$ & $13.39 \pm 1.75$ & & \\
& KGH & $96(25.0)$ & $12.32 \pm 2.22$ & & \\
\hline
\end{tabular}

\section{Discussion}

The purpose of this study was to assess the level of nurses' knowledge, attitude and practice on COVID-19 patients at four selected COVID dedicated hospitals in Dhaka. Considering source of information of COVID-19, majority of nurses (92\%) collected their COVID-19 related information from international health organization sites followed by news media $(87.0 \%)$, government official sites and media $(84.0 \%)$, social media $(81.0 \%)$ and journal $(45.0 \%)$. This finding was consistent with the prior study of Saqlain et al. ${ }^{24}$ In the study of Saqlain most of the participants $(87.68 \%)$ used social media as main source of information. Similarly a study of Bhagavathula et al found that more than $60.0 \%$ respondents used social media to seek information regarding COVID-19. ${ }^{23}$ Regarding hospital facilities, only $37.0 \%$ nurses had received basic training on COVID-19 and same percent of nurses received hand hygiene training. Nearly half of the nurses $(47.0 \%)$ received training on use of PPE and $38.0 \%$ nurses had received training on environmental prevention. Above half $(51.0 \%)$ of the nurses stated that hospital provided dedicated area for risk assessment of COVID-19 patients. Around $58.0 \%$ nurses reported that liquid soaps were available of the communal area in the hospitals. Most of the nurses $(63.0 \%)$ said that rules and facilities for maintain physical distance existed in the hospitals. Most of the nurses (77.0\%) also mentioned that quarantine facilities were provided for nurses with suspected symptoms. Large portion of nurses $(75.0 \%)$ reported that hospital authority encouraged nurses to stay home with COVID-19 symptoms. The current study findings related to source of information on COVID-19 are nearly consistent with the previous study conducted by Saqlain et al. ${ }^{24}$ The reasons for consistent findings might be due to similar characteristics, facilities, policies or rules and regulation of the hospitals to manage the COVID19 patients. 
Current study result showed that the mean score of nurses' knowledge on COVID-19 was 34.15 which indicated moderate level. This finding is inconsistent with the previous study of ZhengjiangJin et al in China. ${ }^{28}$ In the study of China, nurses had better knowledge on COVID-19 in comparison to current study. The difference might be due to the sources of information about COVID-19 were not available or differences in educational background or different healthcare context. Same study of Mahmud Saqlain et al found that nurses had good knowledge than the present study. ${ }^{24}$ The dissimilar result may be because of majority of nurses had not received any basic training on COVID-19. According to item analysis, $100 \%$ nurses answered correctly about fever as a symptom of COVID-19. Majority of nurses answered correctly about mode of transmission of COVID-19 such as Air (99.0\%), contact with infected or carriers $(97.0 \%)$. Correctly answered about the symptoms such as difficulty in breathing $(97.0 \%)$, Sore throat $(96.0 \%)$, runny nose and dry cough $(95.0 \%)$, diarrhea $(84.0 \%)$, headache $(83.0 \%)$, loss of taste and smell $(79.0 \%)$, myalgia (muscle pain) $(73.0 \%$ ), and loss of appetite $(70.0 \%)$. Majority of the nurses $(94.0 \%)$ answered correctly that COVID-19 virus spreads via respiratory droplets of infected individuals. And $92.0 \%$ nurses answered correctly that people in contact with COVID-19 infected person should be immediately isolated for 14 days similarly around $85 \%$ nurses answered correctly that isolation and treatment of infected person with COVID-19 effectively reduce the spread of virus. However, most of the nurses $(75.0 \%)$ answered correctly that in order to prevent COVID-19 individuals should avoid going to crowded places. The current study results regarding item analysis were quite similar with the previous study of Egypt, India, and Nepal. ${ }^{30-32}$ The findings might be due to as anew emerging disease, sign and symptoms, mode of transmission, prevention and management of this fatal disease has not yet been identified. Treatment guidelines or nursing management has not been developed.

Considering nurses attitude on COVID-19, the mean score was $27.60(\mathrm{SD}=3.50)$ considered as neutral attitude and the total item mean score of nurses' practice was calculated as $13.12(\mathrm{SD}=1.78)$ ranging from 10-20 which was considered as moderate. These findings were consistent with the previous study of Mahmud Saqlain et al..$^{24}$ Neutral attitude and moderate practice found in current study are inconsistent with the findings of Zhong, Luo and LiZhong, Luo and $\mathrm{Li}$ found positive attitude and good practice of nurses on COVID-19 infection. ${ }^{33}$ The possible explanation might be due to inadequate management training of nurses and resources for COVID -19 at this study places. According to item analysis, Nurses mostly $(75.0 \%)$ agreed with the statement of a clean, non-sterile, disposable isolation gown must be worn and tied On back with full coverage. Majority of nurses (72.0\%) expressed their opinion that hand washing can prevent from getting infected by COVID-19 virus, whereas majority $(93.0 \%)$ of nurses expressed that eyes, mouth should be covered with gloves and masks and avoid touching until proper hand hygiene performed. In practice items, (98.0\%) always maintained hand hygiene while caring for suspected cases and (97.0\%) followed the country guidelines of COVID-19. A large portion of nurses $(90.0 \%)$ used PPE when take in care of suspected cases. (93.0\%) used masks when in contact with patients. However about $85.0 \%$ nurses refrained from shaking hands and most of them $(95.0 \%)$ had washed their hands before and after handling each patient. Almost all of the nurses $(96.0 \%)$ tried to keep strong mind of corona infected person. The item analyses of the present study are comparable with previous studies conducted in India and Egypt. ${ }^{29}$ Nurses' attitudes in each of the item may be reflected with information received from electronic print media, television or newspaper, breaking news and World Health Organization guidelines or health bulletin.

The present study was to be found a significant correlation between study places and nurses practice score on COVID-19. It means that nurses' working at BSMMU did better practice than those who were working at $\mathrm{MMCH}, \mathrm{DMCH}$ and $\mathrm{KGH}$ respectively. The finding of the current study is similar with the previous study of India. In Indian study, nurses working at private hospital had better practice than those who were working in the public hospitals. The reasons may be due to all required facilities like better isolation environment, good infection prevention and control practices, good hygiene practice and diagnostic procedures of COVID-19 patients. All these facilities and services are available in the private hospitals. ${ }^{30}$

A negative relationship between knowledge and attitude $(\mathrm{r}=-.178, p=.000)$. It means that knowledge is increased but attitude remain unchanged. In contrast, there is no relationship between attitudes and practice and between knowledge and practice respectively. These findings are inconsistent with the previous study as knowledge is significantly related to attitude and also reflected by good practices. ${ }^{24}$ That may be due 
to differences in hospital policy, educational background, and hospital facilities.

\section{Conclusion}

Study findings suggest that hospital policy along with in-service education and training is needed to enhance nurses' competencies in order to improve the knowledge, attitude and practice of nurses on COVID-19 patient care at COVID dedicated hospitals.

Conflict of interest: The authors declare no conflicts of interest regarding this study.

Funding: None

Ethical approval: IRB of BSMMU, Dhaka.

Submitted: $15^{\text {th }}$ October, 2020

Final revision received: $22^{\text {nd }}$ November, 2020

Accepted: $25^{\text {th }}$ November, 2020

Published: $1^{\text {st }}$ December, 2020

\section{Acknowledgements}

Authors like to extend sincere gratitude towards the authority of BSMMU, DMCH, MMCH and $\mathrm{KGH}$ for providing permission to collect the data and participants and teachers who provided support at every step of this research.

\section{References}

1. Cascella M, Rajnik M, Cuomo A et al. Features, evaluation and treatment coronavirus (COVID19). [Updated 2020 May 18]. StatPearls [Internet]. Treasure Island (FL): StatPearls Publishing; 2020. Jan.

URL:www.ncbi.nlm.nih.gov/books/NBK554776/

2. Backer J, Klinkenberg D, Wallinga J. Incubation period of 2019 novel coronavirus (2019-nCoV) infections among travellers from Wuhan, China, Euro Surveill. 2020; 25:2000062.

DOI: 10.2807/1560-7917.ES.2020.25. 5.2000062.

3. Rahman SMM, Akter A, Mostari KF, Ferdousi S, Ummon IJ, Maafi SM et al. Assessment of knowledge, attitudes and practices towards prevention of corronavirus disease (COVID-19) among Bangladeshi Population. Bangladesh Med Res Counc Bull. 2020; 46: 73-82. DOI: $103329 / \mathrm{bmrc} . v 46 \mathrm{i} 2.49015$.

4. World Health Organization. Coronavirus Disease 2019 (COVID-19): Situation Report. Genva: World Health Organization; 2020. URL:www.who.int/emergencies/diseases/novelcoronavirus-2019.

5. WHO, 21, January 2020. Novel coronavirus (2019-nCoV) situation report-1. URL:www.who.int/docs/default-source/ coronaviruse/ situation-reports/20200121-sitrep1-2019-ncov.pdf
6. Coronavirus update Bangladesh 28 October 2020. Institute of Epidemiology, Disease Control \& Research (IEDR), Dhaka, (October, 2020).

7. International Council of Nurses (ICN). 90,000 healthcare workers infected with COVID-19: ICN; Geneva: 2020 May.

URL:www.aa.com.tr/en/europe/90-000-healthcareworkers-infected-with-covid-19-cn/1831765

8. World Health Organization. Coronavirus Disease (COVID-19) Outbreak: Rights, roles and responsibilities of health workers, including key considerations for occupational safety and health. (2020). Retrieved May 13, 2020 from www.who.int/publi cations-detai 1/coronaviru sdisea se-(covid -19)-outbreak.

9. WHO. Coronavirus disease 2019 (COVID-19): World Health Organization. 2020. [Online]. Retrieved May 13, 2020.

URL:www.who.int/emerg encie s/diseases/novel -coronaviru s-2019

10. Wu Z, McGoogan JM. Characteristics of and important lessons from the coronavirus disease 2019 (COVID-19) outbreak in China: Summary of a report of 72314 cases from the Chinese center for disease control and prevention. JAMA. 2020.

DOI: $10.1001 /$ jama.2020.2648.

11. Bleibtreu A, Bertine M, Bertin C, HouhouFidouh N, Visseaux B. Focus on Middle East respiratory syndrome coronavirus (MERS-CoV). Med Maladies Infect. 2019; 50:243-251. DOI: $10.1016 /$ j.medmal.2019.10.004.

12. Velavan TP, Meyer CG. The COVID-19 epidemic. Tropical Medicine and International Health. 2020. 25: 278-280.

DOI: $10.1111 /$ tmi.13383. PMC 7169770.

13. Hopkins C. Loss of sense of smell as marker of COVID-19 infection. Ear, Nose and Throat surgery body of United Kingdom. Retrieved 28 March 2020.

14. How COVID-19 Spreads. U.S. Centers for Disease Control and Prevention (CDC). 2 April 2020. Archived from the original on 3 April 2020. Retrieved 3 April 2020 .

15. Symptoms of Novel Coronavirus (2019-nCoV). U.S. Centers for Disease Control and Prevention (CDC). 10 February 2020. Retrieved 11 February 202028.

16. Mannan KA, Farhana KM. The COVID-19 pandemic: challenges and reality of quarantine, isolation and social distancing for the returnee migrants in Bangladesh. Munich Personal RePEc Archive, 2020; 9: 27-41. 
17. Zhou M, Tang F, Wang Y, Nie H, Zhang L, You $\mathrm{G}$, et al. Knowledge, attitude and practice regarding COVID-19 among health care workers in Henan, China. J Hosp Infect 2020;105:183-7.

18. Mannan DK, Mannan KA. Knowledge and perception towards Novel Coronavirus (COVID 19) in Bangladesh. Int Res J Bus Soc Sci. 2020;6:245.

19. COVID-19 Bangladesh Update, 28 October 2020. France in Bangladesh, Embassy of France in Dhaka.https://bd.ambafrance.org/COVID-19Bangladesh-Update-28-October-2020-2332

20. Bangladesh Coronavirus (COVID-19) Tracker Map.

URL:www.accuweather.com > bd > national > covid-19 Date: 28.10 .2020

21. Mystery pneumonia virus probed in China. BBC News. 3 January 2020. Archived from the original on 5 January 2020. Retrieved 29 January 2020

22. Chang D, Lin M, Wei L, Xie L, Zhu G, Charles $\mathrm{S}$. et al. Epidemiologic and Clinical Characteristics of Novel Coronavirus Infections Involving 13 Patients Outside Wuhan, China. 2020 March; JAMA, 323: 1092-93

23. Bhagavathula AS, Shehab A. The story of Mysterious pneumonia and the response to deadly novel coronavirus (2019-nCoV): so far!.New Emirates Medical Journal. 2020; $1: 7-10$.

DOI: $10.2174 / 0250688202001010007$.

24. Saqlain M, Munir MM, Ur Rehman, S, et al. Knowledge, attitude, practice and perceived barriers among healthcare professionals regarding COVID-19: a cross-sectional survey from Pakistan. MedRxiv. 2020.

DOI: 10.1101/2020.04.13.20063 198 .

25. Mystery pneumonia virus probed in China. BBC News. 3 January 2020. Archived from the original on 5 January 2020. Retrieved 29 January 2020.

26. Mannan DKA, Mannan KA. Knowledge and perception towards novel coronavirus (COVID
19) in Bangladesh. International Research Journal of Business and Social Science. 2020;6 DOI: $10.2139 /$ ssrn.3576523.

27. Farhana KM, Mannan KA. (2020). Knowledge and perception towards Novel Coronavirus (COVID 19) in Bangladesh. International Research Journal of Business and Social Science, 2020; 6, 76-9.

28. ZhengjiangJin, Lan Luo, Xinyun Lei et al.Knowledge, Attitude, and Practice of Nurses Towards the Prevention and Control of COVID19, Research Square,

DOI: $10.21203 /$ rs.3.rs-45450/v1.

29. Wahed WAY, Hefzy EM, Ahmed MI, Hamed NS. Assessment of Knowledge, Attitudes, and Perception of Health Care Workers Regarding COVID-19: a cross-sectional study from Egypt. Journal of Community Health, 2020; 45:1242-1251. DOI: $10.1007 / \mathrm{s} 10900-020-00882-0$.

30. Patidar K, Sharma M, Gautam A, Sharma DK, Jain J. COVID-19 Knowledge and Perception among Budding Nurses: A Questionnaire-Based Survey. IJNR, 2020; 6:1-7.

31. Kafle A, Pandit Pahari S, Khanal S, Baral K, Pathak K, Baral S, Kafle A, Dahal M. Knowledge regarding COVID-19 among Registered Nurses of Pokhara, Nepal. Europasian J Med Sci.2020;2(Covid-19 Special Issue):53-59. DOI: 10.46405/ejms.v2i2.88.

32. Saha AK, Mittra CR, Khatun RR, Reza HM. Nurses' Knowledge and Practices Regarding Prevention and Control of COVID-19 Infection in a Tertiary Level Hospital, Bangladesh Journal of Infectious Diseases, 2020;7: 27-33. DOI: $10.3329 /$ bjid.v7i00.50159.

33. Zhong BL, Luo W, Li HM. Knowledge, attitudes, and practices towards COVID- 19 among Chinese residents during the rapid rise period of the COVID-19 outbreak: a quick online cross-sectional survey. Int $\mathrm{J}$ Biol Sci. 2020; 16:1745-1752.

DOI: $10.7150 /$ ijbs.45221. 